\title{
Bolus size and PCA morphine requirements
}

To the Editor:

We read with interest the article by Park et al. ${ }^{1}$ who concluded that oral clonidine reduces postoperative PCA morphine requirements. We do not contest that oral clonidine can enhance postoperative analgesia but their conclusions have to be balanced with regards to the lack of randomization in PCA bolus dose (l or $2 \mathrm{mg}$ ).

Bolus size has a major impact on morphine consumption. This has been recently reviewed by our Acute Pain Service in 313 postsurgical patients treated with intravenous PCA. The major factors that influenced morphine consumption were: age, weight and bolus size. In our patients, a $1.5 \mathrm{mg}$ bolus of morphine did not improve Visual Analogue Scale pain scores compared with a $1 \mathrm{mg}$ bolus but it increased morphine consumption. In the study of Park et al., the magnitude of the opioid-sparing effect and the lower incidence of side effects reported in the clonidine group could have been influenced by inconstant bolus doses.

We would like to emphasize that the bolus size should be standardized in any study comparing iv PCA morphine consumption.

V. Delire MD, S.M. Broka MD, Yvoir, Belgium

\section{REFERENCE}

1 Park J, Forrest J, Kolesar R, Bhola D, Beattie S, Chu C. Oral clonidine reduces postoperative PCA morphine requirements. Can J Anaesth 1996; 43: 900-6.

\section{Erratum}

C. Ananthanarayan, A.F.D. Cole, M. Kazdan.

Difficult intubation and brain-stem anaesthesia. Can J Anaesth 1997; 44: 658-61.

Please note the typographic error as follows: Page 659, (2nd line from the bottom of the left column) should read:

"A largyngeal mask airway was subsequently inserted but the cuff proved to ..." 